\title{
Evaluasi Sistem Informasi Akademik Menggunakan Framework Cobit 4.1 pada Stikes Aisyiyah Surakarta
}

\author{
Mohammad Fitra Ashari ${ }^{1}$; Andriani $\mathrm{KKW}^{2}{ }^{2}$; Setiyowati ${ }^{3)}$ \\ ${ }^{1)}$ Program Studi Sistem Informasi, STMIK Sinar Nusantara \\ 2) Program Studi Komputerisasi Akuntansi, STMIK Sinar Nusantara \\ 3) Program Studi Manajemen Informatika, STMIK Sinar Nusantara \\ ${ }^{1)}$ fitra.drive@gmailcom; ${ }^{2)}$ andrianikkw@sinus.ac.id; ${ }^{3)}$ setiyowati@sinus.ac.id
}

\begin{abstract}
The title of this research report is The Evaluation of Academic Information System (SIAKAD) STIKES Aisyiyah Surakarta using Framework COBIT 4.1. The purpose of this research is to know the level of maturity of the academic Information System (SIAKAD) and formulate recommendations from these results so that it can be useful to assist in the development of academic systems according to standards set by Framework COBIT 4.1 The methods in this research is data collection (observation, interviews, library study, business document study and questionnaire) and data analysis (calculation of data obtained and analyzed to the final recommendation phase). The result of the evaluation is well managed academic information system. The level of maturity in sub-domains DS1 (Service level management framework), DS5 (System security), and DS10 (Managing problems) is at level 4, which means (managed and measurable). The agency has been concerned and aware of the importance of Service, system security, and management of problems already having only a few procedures with less optimal application such as the service of academic information system that has not been connected to the bank payment system.
\end{abstract}

Keywords: Information System, Deliver and Support, COBIT 4.1, Maturity Level

\section{PENDAHULUAN}

STIKES Aisyiyah adalah perguruan tinggi yang berada di surakarta dan sudah cukup lama memanfaatkan sistem informasi. Dalam menjalankan proses akademisnya, STIKES Aisyiyah didukung dengan sistem yang disebut Sistem Informasi Akademik (SIAKAD).

Meskipun sudah dilakukan evaluasi oleh Pusat Penjaminan Mutu namun sistem yang berjalan masih banyak kendala yang dihadapi, seperti keamanan sistem yang belum terjamin, jika melakukan pembayaran tidak langsung tervalidasi, mahasiswa tidak dapat mengambil mata kuliah dari kelas lain ketika pendaftaran KRS online, maka perlu dilakukan evaluasi guna memperoleh rekomendasi perbaikan yang dapat membantu pengembangan sistem informasi yang berjalan.

Untuk melakukan evaluasi sistem memerlukan kerangka kerja atau framework sebagai standar pengelolaan TI. Framework yang digunakan pada penelitian ini adalah COBIT 4.1

Berdasarkan uraian-uraian di atas maka ditentukan permasalahan sebagai bahan penelitian. Adapun judul yang dipilih yaitu "Evaluasi Sistem Informasi Akademik (SIAKAD) Pada STIKES Aisyiyah Surakarta Menggunakan Framework COBIT 4.1".

\section{TINJAUAN PUSTAKA}

\subsection{Penelitian Terdahulu}

Penelitian terdahulu telah dilakukan oleh Eka Mahardika dengan judul "Analisis Tata Kelola TI Berdasarkan Domain Deliver and Support (DS5) untuk Memastikan Keamanan Sistem Menggunakan Framework COBIT 4.1 pada Universitas Dian Nuswantoro Semarang". Hasil penelitian tersebut diketahui tingkat kematangan (maturity level) pengelolaan proses untuk memastikan keamanan sistem yang ada di Udinus menurut domain DS5 Cobit 4.1 ada di level 2,03 yang termasuk dalam skala repeatable but instituitive atau tingkat kematangan 2 [1].

Neni Purwati melakukan penelitian berjudul "Audit Sistem Informasi Akademik Menggunakan Framework Cobit 4.1 (Studi Kasus Ibi Darmajaya)". Hasilnya adalah tingkat kematangan (maturity level) yang ada pada setiap proses TI yang terdapat dalam domain Planning and Organization (PO) dan Delivery and Support (DS) pada umumnya berada di level 3 (defined process) [2].

Penelitian yang dilakukan oleh Rendra Nasrul dan Wasilah membahas tentang "Penggunaan Metode COBIT Framework 4.1 dalam Mengaudit Sistem Informasi Akademik 
(SIAKAD) pada IAIN RADEN INTAN LAMPUNG". Hasil evaluasi diperolehnya bukti bahwa institusi mengetahui adanya permasalahan yang harus diatasi, dan telah diproses menggunakan metode yang telah di standarkan dalam penyelesaiannya [3].

\subsection{Evaluasi}

Kegiatan untuk mengumpulkan informasi tentang bekerjanya sesuatu yang selanjutnya informasi tersebut digunakan untuk menentukan alternatif yang tepat dalam mengambil keputusan [4].

\subsection{Sistem}

Sekumpulan komponen yang saling berhubungan dan bekerja bersama untuk mencapai suatu tujuan [5].

\subsection{Informasi}

Data yang telah diorganisasi dan telah memiliki kegunaan dan manfaat [6].

\subsection{Sistem Informasi}

Sebuah rangkaian prosedur formal dimana data dikelompokkan, diproses menjadi informasi, dan didistribusikan kepada pemakai [7].

\subsection{Sistem Informasi Akademik}

Sistem yang memberikan layanan informasi yang berupa data dalam hal yang berhubungan dengan akademik. Dimana dalam hal ini pelayanan yang diberikan yaitu seperti : penyimpanan data untuk siswa baru, penentuan kelas, penentuan jadwal pelajaran, pembuatan jadwal mengajar, pembagian wali kelas, proses penilaian [8].

\subsection{Evaluasi Sistem Informasi Akademik Menggunakan Cobit}

Kegiatan untuk mengumpulkan informasi tentang bekerjanya sesuatu yang selanjutnya informasi tersebut digunakan untuk menentukan alternatif yang tepat dalam mengambil keputusan adalah evaluasi [4].

Sistem yang memberikan layanan informasi yang berupa data dalam hal yang berhubungan dengan akademik. Dimana dalam hal ini pelayanan yang diberikan yaitu seperti : penyimpanan data untuk siswa baru, penentuan kelas, penentuan jadwal pelajaran, pembuatan jadwal mengajar, pembagian wali kelas, proses penilaian adalah Sistem Informasi Akademik [8].

COBIT (Control Objectives for Information and Related Technology) merupakan kerangka kerja tata kelola $\mathrm{TI}$ dan set alat pendukung yang memungkinkan manajer untuk menjembatani kesenjangan/celah diantara kebutuhan control, masalah teknis dan risiko bisnis [9].

Berdasarkan keterangan dari ahli diatas diketahui bahwa Evaluasi Sistem Infromasi Akademik Menggunakan Cobit merupakan proses memberikan atau menentukan nilai perangkat lunak yang berhubungan dengan kegiatan akademis menggunakan kerangka kerja cobit yang berguna menghitung kesenjangan/celah.

\subsection{COBIT 4.1}

COBIT dirancang tidak hanya untuk kalangan teknologi informasi atau penyedia layanan $\mathrm{TI}$, melainkan dirancang untuk pengguna lain maupun editor, yang lebih penting adalah COBIT merupakan panduan yang komprehensif bagi manajemen dan pemilik bisnis proses. Cobit memberikan infomasi yang dibutuhkan perusahaan serta untuk mencapai tujuan bisnis perusahaan diperlukan investasi dalam mengelola dan mengendalikan sumber daya $\mathrm{TI}$.

COBIT mendefinisikan aktivitas IT ke dalam empat domain yaitu Plan and Organize (PO), Acquire and Implement (AI), Delivery and Support (DS), dan Monitor and Evaluate (ME). Adapun penjelasan dari empat domain tersebut adalah sebagai berikut [10]:

a. Plan and Organise (PO) Domain ini mencakup strategi, taktik dan identifikasi kontribusi terbaik $\mathrm{TI}$ demi pencapaian tujuan organisasi.

b. Acquire and Implement (Al) Domain ini menitikberatkan pada pengadaan dan penerapan, untuk merealisasikan strategi $\mathrm{TI}$, perlu dilakukan pengidentifikasian, pengembangan dan perolehan solusi $\mathrm{TI}$, sesuai dengan yang akan diimplementasikan dan diintegrasikan ke dalam proses bisnis.

c. Deliver and Support (DS) Domain ini fokus terhadap penyampaian jasa yang sesungguhnya diperlukan, termasuk penyediaan layanan, manajemen keamanan dan kontinuitasnya, jasa dukungan kepada user dan manajemen data dan fasilitas operasi.

d. Monitor and Evaluate (ME) Pada domain ini akan ditekankan kepada pentingnya semua proses teknologi informasi perlu diakses secara berkala untuk menjaga kualitas dan kesesuaian dengan standar yang telah ditetapkan.

\subsection{Maturity Level}

Maturity level adalah suatu metode untuk mengukur level pengembangan manajemen proses, yang berarti adalah mengukur sejauh mana kapabilitas manajemen tersebut. Seberapa bagusnya pengembangan atau kapabilitas manajemen tergantung pada 
tercapainya tujuan-tujuan COBIT. Sebagai contoh adalah ada beberapa proses dan sistem kritikal yang membutuhkan manajemen keamanan yang lebih ketat dibanding proses dan sistem lain yang tidak begitu kritikal. Di sisi lain, derajat dan kepuasan pengendalian yang dibutuhkan untuk diaplikasikan pada suatu proses adalah didorong pada selera resiko enterprise dan kebutuhan kepatuhan yang diterapkan.

Penerapan yang tepat pada tata kelola TI di suatu lingkungan enterprise, tergantung pada pencapaian tiga aspek maturity (kemampuan, jangkauan dan kontrol). Peningkatan maturity akan mengurangi resiko dan meningkatkan efisiensi, mendorong berkurangnya kesalahan dan meningkatkan kuantitas proses yang dapat diperkirakan kualitasnya dan mendorong efisiensi biaya terkait dengan penggunaan sumber daya TI. Maturity model dapat digunakan untuk memetakan:

a) Status pengelolaan TI perusahaan pada saat itu.

b) Status standar industri dalam bidang $\mathrm{TI}$ saat ini (sebagai pembanding)

c) Status standar internasional dalam bidang TI saat ini (sebagai pembanding)

d) Strategi pengelolaan $\mathrm{TI}$ perusahaan (ekspetasi perusahaan terhadap posisi pengelolaan TI perusahaan)

Maturity model dibuat berdasarkan metode untuk mengevaluasi organisasi. Model ini merupakan metode skoring yang memungkinkan organisasi untuk memberi ranking bagi dirinya sendiri dari mulai tidak ada kematangan atau 0 (non-exsistent) sampai dengan kematangan yang optimal atau 5 (optimized). Maturity model dibuat berdasarkan prinsip dari 6 atribut berikut :

a. Kepedulian dan komunikasi (Awarness and communication) - AC

b. Kebijakan, standar dan prosedur (Police, standar and procedure) - PSP

c. Perangkat bantu dan otomatisasi (Tools and automation) - TA

d. Ketrampilan dan keahlian (Skills and expertise) - SE

e. Pertanggungjawaban internal dan eksternal (Reponsibility and accountability) - RA

f. Penetapan tujuan dan pengukuran (Goal setting and measurement) - GSM

Pendefinisian model kematangan suatu proses $\mathrm{TI}$ mengacu pada kerangka kerja COBIT secara umum seperti berikut:

a. Level 0 Non-Existent
Instansi sama sekali tidak ada kepedulian terhadap pentingnya teknologi untuk dikelola secara baik oleh manajemen.

b. Level 1 Initial

Instansi aktif melakukan penerapan dan implementasi teknologi informasi sesuai dengan kebutuhan bisnis, namun dilakukan tanpa melakukan perencanaan sebelumnya / Ad-Hoc.

c. Level 2 Repeatable but Intuitive

Instansi memiliki pola yang rutin dilakukan dalam melakukan pengelolaan aktivitas terkait dengan tata kelola IT, namun belum didefinisikan dengan baik dan formal sehingga masih belum konsisten.

d. Level 3 Defined

Instansi telah memiliki prosedur yang diformalkan dan tertulis yang telah disosialisasikan kesegenap jajaran manajemen dan karyawan untuk di patuhi dan dikerjakan dalam aktivitas sehari-hari.

e. Level 4 Managed and Measurable Instansi telah memiliki sejumlah indikator yang dijadikan sebagai tujuan maupun obyektif kinerja setiap penerapan sistem informasi yang ada dan sudah terukur.

f. Level 5 Optimised Instansi telah menerapkan tata kelola teknologi informasi yang mengacu pada "best practice" sehingga penerapan sistemnya sudah optimal.

\subsection{RACl Chart}

RACl (Responsible, Accountable, Consulted and Informed) adalah matriks untuk seluruh aktivitas atau otorisasi keputusan yang harus diambil dalam suatu organisasi yang dikaitkan dengan seluruh pihak.
a. Responsible adalah orang yang melakukan suatu kegiatan atau melakukan pekerjaan.

b. Accountable adalah orang yang bertanggung jawab dan memiliki otoritas untuk memutuskan suatu perkara.

c. Consulted adalah orang yang memberikan umpan balik atau saran dan berkontribusi akan kegiatan tersebut.

d. Informed adalah orang yang mengetahui hasil dari suatu keputusan.

\section{METODE PENELITIAN}

Metode penelitian digunakan untuk mendapatkan informasi maupun data-data sesuai penelitian yang dilakukan, metodenya sebagai berikut. 


\subsection{Alur Penelitian}

Alur penelitian digunakan untuk mempermudah dalam menentukan urutan penelitian sebagai berikut:

a. Pengumpulan Data

Pengumpulan data merupakan cara yang dilakukan peneliti untuk memperoleh informasi yang dibutuhkan dalam rangka mencapai tujuan penelitian dengan cara Observasi, Wawancara, Telaah dokumen bisnis, dan studi literatur.

b. Menentukan Model Evaluasi Sistem dan Domain

Pada tahap ini penulis memilih model evaluasi sistem yaitu menggunakan framework COBIT 4.1 dan menetapkan domain/focus bahasan yang ada dalam COBIT yaitu pada domain Delivery and Support (DS), dalam domain tersebut hanya berfokus pada 3 Subdomain, yaitu DS01 (Menentukan dan mengelola tingkat layanan), DS05 (Memastikan keamanan sistem) dan DS10 (Mengelola masalah).

c. Membuat Kuesioner

Pembuatan kuisioner ini bertujuan untuk mendapatkan gambaran mengenai fakta dan opini lebih cepat dan menyeluruh terhadap responden dari domain Delivery and Support (DS) untuk setiap proses yag terkait, sehingga diketahui tingkat kematanyan (maturity level) pengelolaan teknologi informasi yang telah digunakan STIKES Aisyiyah Surakarta dengan mengacu pada enam atribut COBIT.

d. Menyebarkan Kuesioner

Pengambilan sampel dalam penelitian ini dengan menggunakan teknik Proportionate Simple Random Sampling yaitu pengambilan sampel anggota populasi dilakukan secara acak tanpa memperhatikan strata yang ada dalam populasi itu. Perhitungan sampel dilakukan dengan menggunakan metode slovin, dengan toleransi tingkat kesalahan sebesar $10 \%(0,1)$. Menggunakan rumus sebagai beikut [11]:

$$
n=\frac{N}{1+N e^{2}}
$$

Keterangan:

$$
\begin{array}{ll}
\mathrm{n} & =\text { Jumlah Sample } \\
\mathrm{N} & =\text { Jumlah Populasi } \\
\mathrm{e} & =\text { Batas Toleransi Kesalahan }
\end{array}
$$

Jumlah populasi dari 1378 mahasiswa dan 8 staff. Penyebaran kuesioner diberikan setelah dihitung dengan metode slovin akan didapatkan jumlah sampel sebanyak 94 mahasiswa dan 8 staff yang akan diberikan kuesioner. Pada penentuan responden menggunakan RACl. RACl berguna dalam mengidentifikasi peran dan tanggung jawab dalam suatu organisasi, berikut ini merupakan tabel RACl yang ada pada STIKES Aisyiyah Surakarta :

Tabel 1. RACI

\begin{tabular}{|c|c|c|}
\hline $\begin{array}{c}\text { Responden } \\
\text { RACl }\end{array}$ & Jabatan & Jumlah \\
\hline $\begin{array}{c}\text { Reponsible/ } \\
\text { Pelaksana }\end{array}$ & Staff & 6 \\
\hline $\begin{array}{c}\text { Accountable/ } \\
\text { Penanggung } \\
\text { Jawab }\end{array}$ & Kepala TI & 1 \\
\hline $\begin{array}{c}\text { Consulted/ } \\
\text { Penasehat }\end{array}$ & $\begin{array}{c}\text { Kepala } \\
\text { Akademik }\end{array}$ & 1 \\
\hline $\begin{array}{c}\text { Informed/ } \\
\text { Terinformasi }\end{array}$ & Mahasiswa & 94 \\
\hline
\end{tabular}

e. Analisis Tingkat kematangan saat ini (as-is) Analisis tingkat kematangan saat ini (as-is) diperoleh berdasarkan hasil kuesioner, kemudian nilai atribut proses tersebut diolah dan dihitung sehingga didapatkan nilai tingkat kematangan proses saat ini (as-is) [12]:

$$
\begin{aligned}
& X i=\frac{\sum N a}{\sum R} \\
& \text { Keterangan: } \\
& X i \quad=\text { nilai kema...............(2) } \\
& \sum N a=\text { jumlah nilai tiap atribut } \\
& \sum R \quad=\text { jumlah responden }
\end{aligned}
$$

Setelah didapatkan nilai kematangan atribut, selanjutnya adalah menghitung tingkat kematangan dari Control Objective untuk mendapatkan nilai dari tingkat kematangannya. Rumus dalam menghitung tingkat kematangan $\mathrm{CO}$ ditunjukkan pada rumus berikut [12]:

$$
X_{C O}=\frac{\sum_{6}^{a} X i}{6}
$$

Keterangan:

$$
\begin{aligned}
& X_{c o}=\text { nilai tingkat kematangan } \mathrm{CO} \\
& \sum_{6} N i=\text { nilai kematangan atribut } \\
& =\text { jumlah atribut }
\end{aligned}
$$

f. Analisis Tingkat kematangan dimasa mendatang (to-be)

Analisis tingkat kematangan yang diharapkan diperoleh berdasarkan hasil wawancara dengan pihak terkait, dilihat dari kemampuan pengelolaan $\mathrm{TI}$ pada skala maturity 0 sampai 5 maka pihak STIKES Aisyiyah Surakarta menginginkan nilai tingkat kematangan berada pada level 5 (optimized). 
g. Analisis Kesenjangan (gap)

Setelah diketahui tingkat kematangan saat ini (as-is) maka dibandingkan dengan kematangan yang diharapkan (to-be). Dari perbandingan tersebut maka akan diperoleh kesenjangan (gap) dari proses-proses yang ada, kemudian akan dilakukan analisis proses yang dimiliki kesenjangan dan membutuhkan perbaikan.

h. Merumuskan Rekomendasi

Merumuskan rekomendasi yang diperlukan untuk mengatasi kesenjangan (gap) yang ada. Rekomendasi dibuat berdasarkan hasil pemetaan tingkat kematangan (maturity level) dari hasil data yang diperoleh.

\section{HASIL DAN PEMBAHASAN}

\subsection{Proses Evaluasi}

Evaluasi pada Sistem Informasi Akademik (SIAKAD) di STIKES Aisyiyah Surakarta bertujuan untuk mengetahui tingkat kematangan sistem sesuai metode COBIT 4.1. Tahapan evaluasi dilakukan dengan melakukan pengamatan terhadap sistem SIAKAD yang diterapkan, melakukan wawancara terhadap pengguna dan pengelola terkait kendala yang dihadapi, melakukan studi pustaka, menentukan domain yang akan diambil, lalu membuat kuesioner.

Hasil kuesioner yang sudah disebarkan di olah sehingga dapat diketahui tingkat kematangan saat ini (as-is), melakukan wawancara untuk mengetahui sejauh mana sistem berjalan dan tingkat kematangan yang diharapkan (to-be).

Setelah diketahui tingkat kematangan saat ini (as-is) dan tingkat kematangan yang diharapkan (to-be) maka di dapat nilai kesenjangan (gap). Selanjutnya melakukan identifikasi masalah terkait kesenjangan tersebut dan melakukan perumusan rekomendasi perbaikan.

\subsection{Kuesioner}

Kuesioner diberikan pada responden terkait sistem SIAKAD di STIKES Aisyiyah Surakarta sebanyak 101 responden. Kuesioner berisi pertanyaan yang mengacu pada 6 atribut dengan penilaian sesuai pada level indeks kematangan COBIT 4.1 pada domain DS1 (Pengelolaan Pelayanan), DS5 (Keamanan Sistem) dan DS10 (Pengelolaan Masalah). Berikut ini merupakan penerapan google form dalam pembuatan kuesioner:

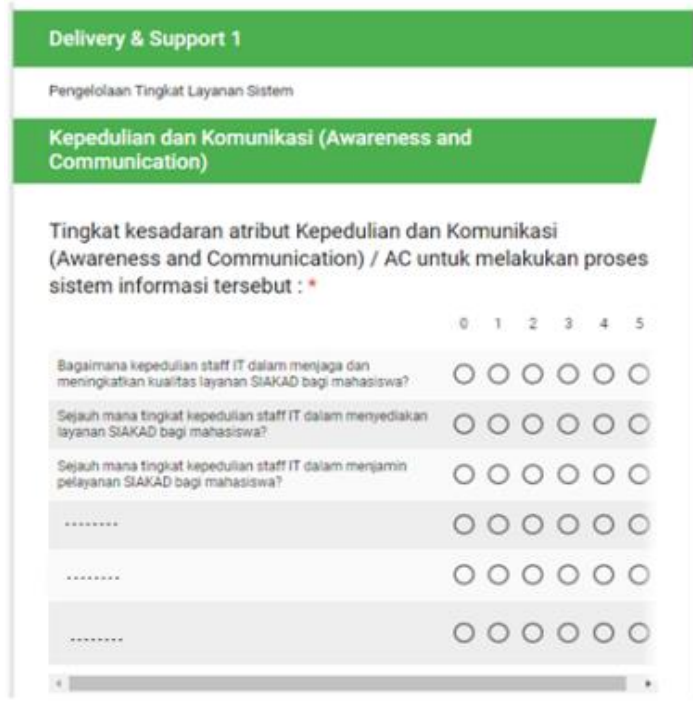

Gambar 1. Kuesioner DS1

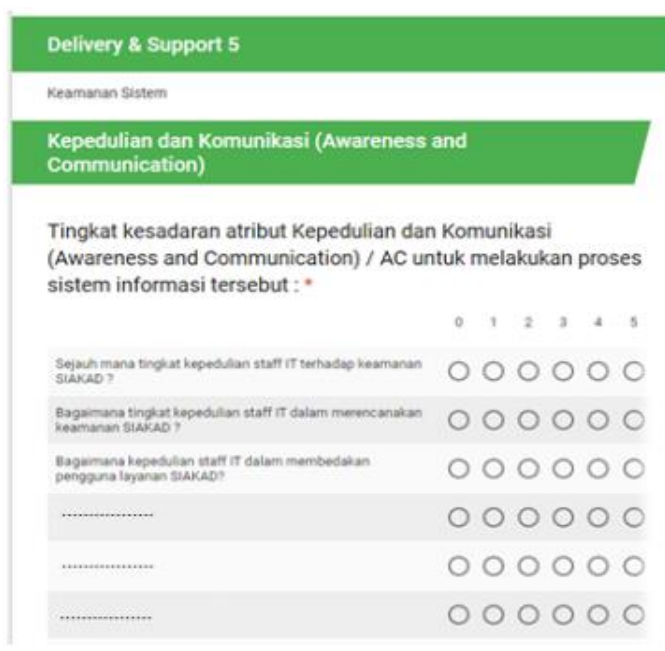

Gambar 2. Kuesioner DS5

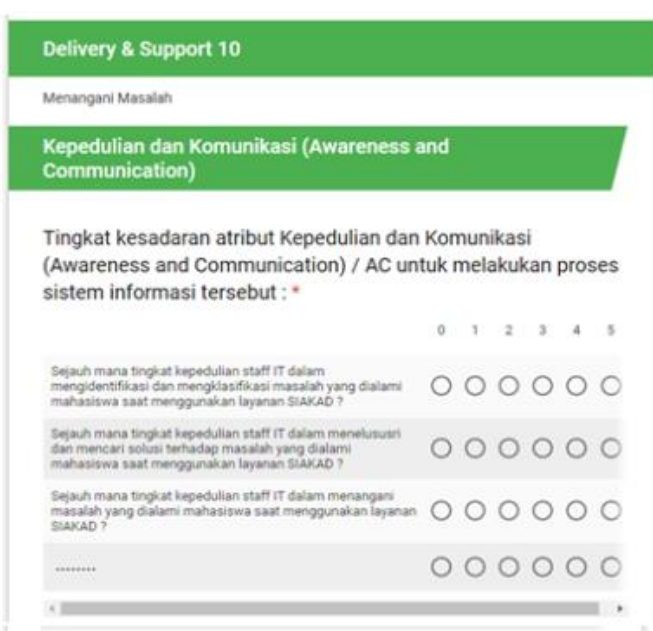

Gambar 3. Kuesioner DS10

\subsection{Perhitungan Tingkat Kematangan Saat Ini (as-is) \\ Kuesioner yang telah disebar akan} diperoleh nilai angka pada tiap atribut, berikut ini merupakan perhitungan untuk mengetahui nilai tingkat kematangan saat ini dari tiap atribut dan $\mathrm{CO}$ menggunakan rumus 2 dan 3 , 
berikut ini hasil perhitungan tingkat kematangan CO DS1 seperti pada Tabel 1.

Tabel 1. Tingkat Kematangan DS1

\begin{tabular}{|c|c|c|c|c|}
\hline $\mathrm{CO}$ & Atribut & $\begin{array}{c}\text { Nilai } \\
\text { Kematan } \\
\text { gan } \\
\text { Atribut } \\
\end{array}$ & $\begin{array}{c}\text { Nilai } \\
\text { Kematan } \\
\text { gan CO }\end{array}$ & $\begin{array}{l}\text { Matur } \\
\text { ity } \\
\text { Level }\end{array}$ \\
\hline \multirow{6}{*}{$\begin{array}{l}\text { DS } \\
1.1\end{array}$} & $A C$ & 3.80 & \multirow{6}{*}{3.83} & \multirow{6}{*}{4} \\
\hline & PSP & 3.87 & & \\
\hline & TA & 3.96 & & \\
\hline & SE & 3.80 & & \\
\hline & RA & 3.92 & & \\
\hline & GSM & 3.68 & & \\
\hline \multirow{6}{*}{$\begin{array}{l}\text { DS } \\
1.2\end{array}$} & $A C$ & 4.03 & \multirow{6}{*}{3.97} & \multirow{6}{*}{4} \\
\hline & PSP & 3.98 & & \\
\hline & TA & 4.0 & & \\
\hline & SE & 3.97 & & \\
\hline & RA & 4.0 & & \\
\hline & GSM & 3.85 & & \\
\hline \multirow{6}{*}{$\begin{array}{l}\text { DS } \\
1.3\end{array}$} & $\mathrm{AC}$ & 3.85 & \multirow{6}{*}{3.92} & \multirow{6}{*}{4} \\
\hline & PSP & 3.88 & & \\
\hline & TA & 3.98 & & \\
\hline & SE & 3.93 & & \\
\hline & RA & 4.11 & & \\
\hline & GSM & 3.81 & & \\
\hline \multirow{6}{*}{$\begin{array}{l}\text { DS } \\
1.4\end{array}$} & $A C$ & 3.90 & \multirow{6}{*}{3.93} & \multirow{6}{*}{4} \\
\hline & PSP & 3.87 & & \\
\hline & TA & 3.86 & & \\
\hline & SE & 3.93 & & \\
\hline & $\mathrm{RA}$ & 4.12 & & \\
\hline & GSM & 3.90 & & \\
\hline \multirow{6}{*}{$\begin{array}{l}\text { DS } \\
1.5\end{array}$} & $A C$ & 3.86 & \multirow{6}{*}{3.95} & \multirow{6}{*}{4} \\
\hline & PSP & 3.88 & & \\
\hline & TA & 3.91 & & \\
\hline & SE & 4.01 & & \\
\hline & $\mathrm{RA}$ & 4.09 & & \\
\hline & GSM & 3.85 & & \\
\hline \multirow{6}{*}{$\begin{array}{l}\text { DS } \\
1.6\end{array}$} & $\mathrm{AC}$ & 3.92 & \multirow{6}{*}{3.99} & \multirow{6}{*}{4} \\
\hline & PSP & 4.01 & & \\
\hline & TA & 3.93 & & \\
\hline & SE & 3.93 & & \\
\hline & RA & 4.19 & & \\
\hline & GSM & 3.96 & & \\
\hline \multicolumn{3}{|c|}{ Rata-rata CO DS1 } & 3,94 & 4 \\
\hline
\end{tabular}

a. Perhitungan DS5

Berikut salah satu contoh penerapan rumusnya pada atribut awareness and communication. Hasil perhitungan tingkat kematangan CO DS5 ditunjukkan pada Tabel 2.

Tabel 2. Tingkat Kematangan DS5

\begin{tabular}{|c|c|c|c|c|}
\hline CO & Atribut & $\begin{array}{c}\text { Nilai } \\
\text { Kematan } \\
\text { gan } \\
\text { Atribut }\end{array}$ & $\begin{array}{c}\text { Nilai } \\
\text { Kematan } \\
\text { gan CO }\end{array}$ & $\begin{array}{c}\text { Matur } \\
\text { ity } \\
\text { Level }\end{array}$ \\
\hline DS & AC & 3.80 & \multirow{2}{*}{3.87} & 4 \\
\cline { 2 - 3 } 5.1 & PSP & 3.92 & \multirow{2}{*}{} \\
\hline
\end{tabular}

\begin{tabular}{|c|c|c|c|c|}
\hline \multirow[t]{5}{*}{$\mathrm{CO}$} & Atribut & $\begin{array}{c}\text { Nilai } \\
\text { Kematan } \\
\text { gan } \\
\text { Atribut }\end{array}$ & $\begin{array}{c}\text { Nilai } \\
\text { Kematan } \\
\text { gan CO }\end{array}$ & $\begin{array}{c}\text { Matur } \\
\text { ity } \\
\text { Level }\end{array}$ \\
\hline & TA & 3.94 & & \\
\hline & SE & 3.77 & & \\
\hline & RA & 3.98 & & \\
\hline & GSM & 3.83 & & \\
\hline \multirow{6}{*}{$\begin{array}{l}\text { DS } \\
5.2\end{array}$} & $A C$ & 3.90 & \multirow{6}{*}{3.93} & \multirow{6}{*}{4} \\
\hline & PSP & 3.97 & & \\
\hline & TA & 3.98 & & \\
\hline & SE & 3.82 & & \\
\hline & RA & 4.00 & & \\
\hline & GSM & 3.91 & & \\
\hline \multirow{6}{*}{$\begin{array}{l}\mathrm{DS} \\
5.3\end{array}$} & AC & 3.90 & \multirow{6}{*}{3.93} & \multirow{6}{*}{4} \\
\hline & PSP & 3.95 & & \\
\hline & TA & 3.99 & & \\
\hline & SE & 3.83 & & \\
\hline & RA & 4.07 & & \\
\hline & GSM & 3.88 & & \\
\hline DS & $\mathrm{AC}$ & 3.96 & \multirow{6}{*}{4.01} & \multirow{6}{*}{4} \\
\hline \multirow[t]{5}{*}{5.4} & PSP & 4.11 & & \\
\hline & TA & 4.02 & & \\
\hline & SE & 4.00 & & \\
\hline & RA & 3.99 & & \\
\hline & GSM & 3.98 & & \\
\hline DS & $A C$ & 3.86 & \multirow{6}{*}{4.01} & \multirow{6}{*}{4} \\
\hline \multirow[t]{5}{*}{5.5} & PSP & 4.07 & & \\
\hline & TA & 4.08 & & \\
\hline & SE & 3.99 & & \\
\hline & RA & 4.08 & & \\
\hline & GSM & 3.95 & & \\
\hline DS & $A C$ & 4.00 & \multirow{6}{*}{4.03} & \multirow{6}{*}{4} \\
\hline \multirow[t]{5}{*}{5.6} & PSP & 4.09 & & \\
\hline & TA & 4.00 & & \\
\hline & SE & 4.01 & & \\
\hline & RA & 4.06 & & \\
\hline & GSM & 4.02 & & \\
\hline DS & $A C$ & 4.07 & \multirow{6}{*}{4.03} & \\
\hline \multirow[t]{5}{*}{5.7} & PSP & 4.07 & & \\
\hline & TA & 4.06 & & 4 \\
\hline & SE & 3.94 & & \\
\hline & RA & 4.08 & & \\
\hline & GSM & 3.95 & & \\
\hline DS & $\mathrm{AC}$ & 3.95 & & \\
\hline 5.8 & PSP & 4.11 & & \\
\hline & TA & 4.02 & 404 & 4 \\
\hline & SE & 4.00 & 4.04 & 4 \\
\hline & RA & 4.11 & & \\
\hline & GSM & 4.08 & & \\
\hline DS & $A C$ & 3.88 & & \\
\hline 5.9 & PSP & 3.85 & & \\
\hline & TA & 4.06 & 397 & 4 \\
\hline & SE & 3.93 & 0.51 & 4 \\
\hline & RA & 4.12 & & \\
\hline & GSM & 4.02 & & \\
\hline DS & $\mathrm{AC}$ & 3.96 & & \\
\hline 5.10 & PSP & 3.99 & 39 & 1 \\
\hline & TA & 3.97 & 0.55 & 4 \\
\hline & SE & 4.00 & & \\
\hline
\end{tabular}




\begin{tabular}{|c|c|c|c|c|}
\hline \multirow[t]{3}{*}{$\mathrm{CO}$} & Atribut & $\begin{array}{c}\text { Nilai } \\
\text { Kematan } \\
\text { gan } \\
\text { Atribut }\end{array}$ & $\begin{array}{c}\text { Nilai } \\
\text { Kematan } \\
\text { gan CO }\end{array}$ & $\begin{array}{l}\text { Matur } \\
\text { ity } \\
\text { Level }\end{array}$ \\
\hline & RA & 4.09 & & \\
\hline & GSM & 3.98 & & \\
\hline \multirow{6}{*}{$\begin{array}{c}D S \\
5.11\end{array}$} & $\mathrm{AC}$ & 4.06 & \multirow{6}{*}{4.07} & \multirow{6}{*}{4} \\
\hline & PSP & 4.01 & & \\
\hline & TA & 4.06 & & \\
\hline & SE & 4.04 & & \\
\hline & RA & 4.13 & & \\
\hline & GSM & 4.15 & & \\
\hline \multicolumn{3}{|c|}{ Rata-rata CO DS5 } & 3,99 & 4 \\
\hline
\end{tabular}

b. Perhitungan DS10

Hasil keseluruhan Control Objective DS10 pada Tabel 3.

Tabel 3. Tingkat Kematangan DS10

\begin{tabular}{|c|c|c|c|c|}
\hline $\mathrm{CO}$ & Atribut & $\begin{array}{c}\text { Nilai } \\
\text { Kematan } \\
\text { gan } \\
\text { Atribut }\end{array}$ & $\begin{array}{c}\text { Nilai } \\
\text { Kematan } \\
\text { gan CO }\end{array}$ & $\begin{array}{l}\text { Matur } \\
\text { ity } \\
\text { Level }\end{array}$ \\
\hline \multirow{6}{*}{$\begin{array}{c}\text { DS } \\
10.1\end{array}$} & $A C$ & 3.82 & \multirow{6}{*}{3.89} & \multirow{6}{*}{4} \\
\hline & PSP & 3.90 & & \\
\hline & TA & 3.86 & & \\
\hline & SE & 3.83 & & \\
\hline & RA & 4.06 & & \\
\hline & GSM & 3.93 & & \\
\hline \multirow{6}{*}{$\begin{array}{c}\text { DS } \\
10.2\end{array}$} & $A C$ & 4.00 & \multirow{6}{*}{3.99} & \multirow{6}{*}{4} \\
\hline & PSP & 3.93 & & \\
\hline & TA & 3.97 & & \\
\hline & SE & 3.99 & & \\
\hline & RA & 4.05 & & \\
\hline & GSM & 4.03 & & \\
\hline \multirow{6}{*}{$\begin{array}{c}\text { DS } \\
10.3\end{array}$} & $A C$ & 3.96 & \multirow{6}{*}{4} & \multirow{6}{*}{4} \\
\hline & PSP & 3.94 & & \\
\hline & TA & 3.91 & & \\
\hline & SE & 3.99 & & \\
\hline & RA & 4.06 & & \\
\hline & GSM & 4.16 & & \\
\hline \multirow{6}{*}{$\begin{array}{c}\text { DS } \\
10.4\end{array}$} & $A C$ & 4.02 & \multirow{6}{*}{4.07} & \multirow{6}{*}{4} \\
\hline & PSP & 3.99 & & \\
\hline & TA & 4.06 & & \\
\hline & SE & 4.10 & & \\
\hline & RA & 4.10 & & \\
\hline & GSM & 4.22 & & \\
\hline \multicolumn{3}{|c|}{ rata C } & 3.99 & 4 \\
\hline
\end{tabular}

\subsection{Tingkat Kematangan Harapan (to-be)}

Tingkat kematangan yang diharapkan perusahaan berdasarkan hasil wawancara berada pada level 5 (optimized). Instansi berharap adanya kepedulian, tanggungjawab dan keahlian staff secara optimal untuk meningkatkan pengelolaan layanan SIAKAD agar mencapai tujuan yang ditetapkan.

Tabel 4. Tingkat Kematangan Diharapkan

\begin{tabular}{|c|l|l|c|}
\hline $\begin{array}{c}\text { Atri } \\
\text { but }\end{array}$ & Pertanyaan & \multicolumn{1}{|c|}{ Hasil } & $\begin{array}{l}\text { Matur } \\
\text { ity } \\
\text { Level }\end{array}$ \\
\hline DS1 & $\begin{array}{l}\text { Harapan } \\
\text { kedepan terkait } \\
\text { pengelolaan } \\
\text { pelayanan pada } \\
\text { sistem SIAKAD? }\end{array}$ & $\begin{array}{l}\text { Layanan SIAKAD } \\
\text { dapat diakses lebih } \\
\text { cepat dan optimal, } \\
\text { sistem pembayaran } \\
\text { sudah } \\
\text { terotomatisasi dan } \\
\text { fiturnya sudah } \\
\text { lengkap. }\end{array}$ & 5 \\
\hline DS5 & $\begin{array}{l}\text { Harapan } \\
\text { kedepan } \\
\text { terhadap } \\
\text { keamanan } \\
\text { sistem yang ada } \\
\text { pada SIAKAD? }\end{array}$ & $\begin{array}{l}\text { Keamanan lebih } \\
\text { terjamin, jika ada } \\
\text { serangan dari luar } \\
\text { otomatis terdeteksi } \\
\text { sehingga dapat } \\
\text { segera ditangani. }\end{array}$ & 5 \\
\hline DS & $\begin{array}{l}\text { Harapan } \\
\text { kedepan } \\
\text { terhadap } \\
\text { pengelolaan } \\
\text { masalah terkait } \\
\text { layanan SIAKAD }\end{array}$ & $\begin{array}{l}\text { Masalah yang ada } \\
\text { dapat diselesaikan } \\
\text { lebih cepat dan } \\
\text { maksimal sehingga } \\
\text { tidak mengganggu } \\
\text { kegiatan akademik. }\end{array}$ & 5 \\
\hline
\end{tabular}

\subsection{Analisa Tingkat Kesenjangan (gap)}

Nilai Kesenjangan (gap) didapat dari hasil pengurangan antara nilai kematangan harapan yang diperoleh dari hasil wawancara dengan nilai kematangan saat ini yang diperoleh dari kuesioner, nilai Kesenjangan Control Objective DS1 pada Tabel 5.

Tabel 5. Kesenjangan DS1

\begin{tabular}{|c|c|c|c|}
\hline \multirow{2}{*}{ CO } & \multicolumn{3}{|c|}{ Tingkat kematangan } \\
\cline { 2 - 4 } & $\begin{array}{c}\text { Saat Ini } \\
\text { (as-is) }\end{array}$ & $\begin{array}{c}\text { Diharapka } \\
\mathrm{n} \\
\text { (to-be) }\end{array}$ & $\begin{array}{c}\text { Kesenjangan } \\
(\text { GAP })\end{array}$ \\
\hline DS1.1 & 4 & 5 & 1 \\
\hline DS1.2 & 4 & 5 & 1 \\
\hline DS1.3 & 4 & 5 & 1 \\
\hline DS1.4 & 4 & 5 & 1 \\
\hline DS1.5 & 4 & 5 & 1 \\
\hline DS1.6 & 4 & 5 & 1 \\
\hline
\end{tabular}

Sedangkan hasil kesenjangan Control Objective DS5 ditunjukkan pada Tabel 6.

Tabel 6. Kesenjangan DS5

\begin{tabular}{|c|c|c|c|}
\hline \multirow{2}{*}{ C0 } & \multicolumn{3}{|c|}{ Tingkat kematangan } \\
\cline { 2 - 4 } & $\begin{array}{c}\text { Saat Ini } \\
\text { (as-is) }\end{array}$ & $\begin{array}{c}\text { Diharapka } \\
\mathrm{n} \\
\text { (to-be) }\end{array}$ & $\begin{array}{c}\text { Kesenjangan } \\
(G A P)\end{array}$ \\
\hline DS5.1 & 4 & 5 & 1 \\
\hline DS5.2 & 4 & 5 & 1 \\
\hline DS5.3 & 4 & 5 & 1 \\
\hline DS5.4 & 4 & 5 & 1 \\
\hline DS5.5 & 4 & 5 & 1 \\
\hline DS5.6 & 4 & 5 & 1 \\
\hline DS5.7 & 4 & 5 & 1 \\
\hline DS5.8 & 4 & 5 & 1 \\
\hline DS5.9 & 4 & 5 & 1 \\
\hline DS5.10 & 4 & 5 & 1 \\
\hline
\end{tabular}




\begin{tabular}{|c|c|c|c|}
\hline \multirow{2}{*}{ CO } & \multicolumn{3}{|c|}{ Tingkat kematangan } \\
\cline { 2 - 4 } & $\begin{array}{c}\text { Saat Ini } \\
\text { (as-is) }\end{array}$ & $\begin{array}{c}\text { Diharapka } \\
\mathrm{n} \\
\text { (to-be) }\end{array}$ & $\begin{array}{c}\text { Kesenjangan } \\
(\text { GAP })\end{array}$ \\
\hline DS5.11 & 4 & 5 & 1 \\
\hline
\end{tabular}

Sedangkan hasil kesenjangan sub domain DS10 ditunjukkan pada Tabel 7.

\begin{tabular}{|c|c|c|c|}
\hline \multirow{2}{*}{ CO } & \multicolumn{3}{|c|}{ Tingkat kematangan } \\
\cline { 2 - 4 } & $\begin{array}{c}\text { Saat Ini } \\
\text { (as-is) }\end{array}$ & $\begin{array}{c}\text { Diharapka } \\
\mathrm{n} \\
\text { (to-be) }\end{array}$ & $\begin{array}{c}\text { Kesenjangan } \\
(\text { GAP })\end{array}$ \\
\hline DS10.1 & 4 & 5 & 1 \\
\hline DS10.2 & 4 & 5 & 1 \\
\hline DS10.2 & 4 & 5 & 1 \\
\hline DS10.4 & 4 & 5 & 1 \\
\hline
\end{tabular}

\section{Tabel 7. Kesenjangan DS10}

\subsection{Ringkasan Identifikasi Masalah dan Rekomendasi}

Tabel 8. Ringkasan Identifikasi Masalah dan Rekomendasi DS1

\begin{tabular}{|c|c|c|}
\hline Atribut & Ringkasan Identifikasi Masalah & Rekomendasi \\
\hline $\begin{array}{c}1 \\
A C\end{array}$ & $\begin{array}{l}\text { Kepedulian Instansi terhadap manajemen } \\
\text { tingkat layanan telah dilakukan secara } \\
\text { berkala. Sudah ada tindakan penanganan } \\
\text { yang dilakukan oleh staff IT, namun belum } \\
\text { optimal. }\end{array}$ & $\begin{array}{l}\text { Instansi harus memonitoring setiap pelayanan yang } \\
\text { dilakukan oleh staff kepada mahasiswa dan melakukan } \\
\text { evaluasi pengelolaan pelayanan secara rutin. } \\
\text { Berkoordinasi dengan staff dan melakukan sosialisasi } \\
\text { kepada mahasiswa ketika ada perubahan yang terjadi } \\
\text { pada SIAKAD sehingga tidak mengganggu aktifitas } \\
\text { pelayanan. }\end{array}$ \\
\hline $\begin{array}{c}2 \\
P S P\end{array}$ & $\begin{array}{l}\text { Prosedur dalam manajemen layanan sudah } \\
\text { diformalkan oleh instansi. SOP dalam } \\
\text { pelayanan sudah dilakukan secara } \\
\text { berkelanjutan dan sesuai kebijakan instansi. }\end{array}$ & $\begin{array}{l}\text { Prosedur sudah diformalkan, kedepannya harus } \\
\text { dipertahankan. Penerapan SIAKAD sudah baik dalam } \\
\text { hal pelayanan terhadap mahasiswa, instansi hanya } \\
\text { perlu meningkatkan dan mempertahankan prosedur- } \\
\text { prosedur yang diformalkan. }\end{array}$ \\
\hline$\ldots$ & & $\ldots$. \\
\hline$\stackrel{6}{\mathrm{GSM}}$ & 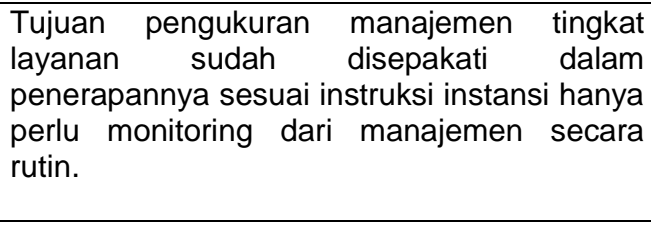 & $\begin{array}{l}\text { Pengawasan secara rutin dilakukan guna } \\
\text { mempermudah dalam mengukur tujuan manajemen } \\
\text { layanan maka didapat nilai kinerja optimal. } \\
\text { Menugaskan staff IT untuk melakukan pengujian } \\
\text { terhadap sistem SIAKAD dan dibuat laporan untuk } \\
\text { pimpinan instansi guna ditindak lanjuti. }\end{array}$ \\
\hline
\end{tabular}

Tabel 9. Ringkasan Identifikasi Masalah dan Rekomendasi DS5

\begin{tabular}{|c|c|c|}
\hline Atribut & Ringkasan Identifikasi Masalah & Rekomendasi \\
\hline \multirow[b]{2}{*}{$\begin{array}{c}1 \\
A C\end{array}$} & $\begin{array}{l}\text { Pengelolaan keamanan sistem yang } \\
\text { dilakukan staff IT sudah ada kepedulian } \\
\text { dalam mengamankan pertukaran data sensitif } \\
\text { sudah ada tindakan menggunakan kriptografi, } \\
\text { keamanan jaringan sudah dikelola dengan } \\
\text { baik, hanya saja masih perlu ditingkatkan lagi } \\
\text { ketingkat yang lebih lanjut dan dilakukan } \\
\text { pendalaman }\end{array}$ & $\begin{array}{l}\text { Staff IT perlu memperhatikan keamanan sistem yang } \\
\text { berjalan. Perlu dilakukan pengujian terhadap keamanan } \\
\text { sistem secara berkala, melakukan pemantauan } \\
\text { terhadap sistem agar dapat diketahui segala aktifitas } \\
\text { yang terjadi sehingga jika terjadi tindak pembobolan } \\
\text { keamanan dapat diketahui dan dilakukan tindakan } \\
\text { mengamankan sistem sesegera mungkin. }\end{array}$ \\
\hline & $\begin{array}{l}\text { Pengelolaan hak akses pengguna ada } \\
\text { kepedulian dan tindakan yang dilakukan, } \\
\text { Perencanaan keamanan sudah ada tindakan, } \\
\text { teknologi keamanan sudah diterapkan, } \\
\text { masalah keamanan sudah ditangani dengan } \\
\text { baik, namun belum ada tindakan pencegahan } \\
\text { yang dilakukan, pengamanan terhadap } \\
\text { perangkat lunak berbahaya sudah ada } \\
\text { tindakan namun dilakukan ketika ada aduan. }\end{array}$ & $\begin{array}{l}\text { Staff IT perlu mencermati setiap aktifitas yang terjadi } \\
\text { didalam sistem SIAKAD dan meninjau perangkat lunak } \\
\text { berbahaya yang mungkin menyerang sistem SIAKAD, } \\
\text { melakukan bakcup sistem secara berkala sehingga } \\
\text { dapat dilakukan restore ketika sistem mengalami } \\
\text { masalah. }\end{array}$ \\
\hline $\begin{array}{c}2 \\
\text { PSP }\end{array}$ & $\begin{array}{l}\text { Standar prosedur dalam pengelolaan } \\
\text { keamanan sistem sudah diterapkan sudah } \\
\text { dilakukan dan ada proses berkelanjutan } \\
\text { sesuai kebijakan instansi namun belum } \\
\text { dilakukan monitoring terhadap penerapan } \\
\text { prosedur untuk mendeteksi adanya kendala. }\end{array}$ & $\begin{array}{l}\text { Prosedur yang diterapkan perlu dipertahankan, } \\
\text { penerapan keamanan sistem sudah cukup baik. } \\
\text { Instansi perlu melakukan monitoring terhadap prosedur } \\
\text { yang dilakukan oleh staff IT dalam mengelola } \\
\text { keamanan sistem, sehingga dapat diketahui kendala } \\
\text { yang dihadapi yang berguna untuk meningkatkan } \\
\text { prosedur secara berkelanjutan. }\end{array}$ \\
\hline$\ldots$ & $\ldots$. & \\
\hline $\begin{array}{c}6 \\
\text { GSM }\end{array}$ & $\begin{array}{l}\text { Penetapan tujuan dalam mengelola } \\
\text { keamanan sistem telah dilakukan namun } \\
\text { dalam penerapan keamanan masih ada celah }\end{array}$ & $\begin{array}{l}\text { Staff IT perlu untuk melakukan monitoring dan } \\
\text { pengujian terhadap keamanan sistem yang berjalan } \\
\text { dan membuat laporan tentang celah yang munkin }\end{array}$ \\
\hline
\end{tabular}




\begin{tabular}{|c|c|l|}
\hline Atribut & \multicolumn{1}{|c|}{ Ringkasan Identifikasi Masalah } & \multicolumn{1}{c|}{ Rekomendasi } \\
\hline & $\begin{array}{l}\text { atau bug yang terjadi didalam sistem, belum } \\
\text { ada pengujian dan monitoring secara berkala } \\
\text { terhadap keamanan sistem. }\end{array}$ & $\begin{array}{l}\text { terjadi sehingga dapat dilakukan tindakan perbaikan } \\
\text { yang dapat berguna meminimalisir tindakan hacking } \\
\text { oleh orang yang tidak bertanggung jawab. }\end{array}$ \\
\hline
\end{tabular}

Tabel 10. Ringkasan Identifikasi Masalah dan Rekomendasi DS10

\begin{tabular}{|c|c|c|}
\hline Atribut & Ringkasan Identifikasi Masalah & Rekomendasi \\
\hline $\begin{array}{c}1 \\
A C\end{array}$ & $\begin{array}{l}\text { Kepedulian staff IT dalam pengelolaan } \\
\text { masalah terkait layanan SIAKAD sudah ada } \\
\text { kepedulian dan tindakan namun belum } \\
\text { maksimal, dan penanganan masalah } \\
\text { dilakukan ketika ada laporan dari pengguna } \\
\text { layanan saja, }\end{array}$ & $\begin{array}{l}\text { Staff IT harus melakukan pengujian terhadap sistem } \\
\text { SIAKAD secara rutin sehingga resiko terjadinya } \\
\text { masalah terkait layanan SIAKAD yang dialami } \\
\text { pengguna dapat diperkecil. Ketika terjadi masalah } \\
\text { terkait layanan SIAKAD harus segera ditangani } \\
\text { sehingga tidak dialami oleh banyak pengguna layanan } \\
\text { yang lain seperti masalah mahasiswa yang belum bisa } \\
\text { mengambil matakuliah dikelas lain ketika mengajukan } \\
\text { KRS, dengan cara merubah kode SQL pada sistem } \\
\text { SIAKAD bagian KRS. }\end{array}$ \\
\hline $\begin{array}{c}2 \\
P S P\end{array}$ & $\begin{array}{l}\text { Standar prosedur dalam pengelolaan } \\
\text { masalah sudah ada dan sudah diterapkan } \\
\text { namun pengawasan terhadap penerapannya } \\
\text { belum dijalankan secara optimal }\end{array}$ & $\begin{array}{l}\text { Prosedur sudah diformalkan, kedepannya harus } \\
\text { dipertahankan. Pengelolaan sudah cukup baik. Instansi } \\
\text { harus melakukan pengawasan dalam pengelolaan } \\
\text { masalah agar prosedur dalam menangani masalah } \\
\text { dapat dimaksimalkan. }\end{array}$ \\
\hline$\ldots$ & $\ldots$. & $\ldots$ \\
\hline$\stackrel{6}{\mathrm{GSM}}$ & $\begin{array}{l}\text { Penetapan pengukuran tujuan manajemen } \\
\text { masalah telah dilakukan pemantauan namun } \\
\text { tindakan penanganan dilakukan ketika } \\
\text { muncul masalah saja. }\end{array}$ & $\begin{array}{l}\text { Monitoring secara berkala perlu dilakukan guna } \\
\text { mengetahui tingkat pengelolaan masalah sehingga } \\
\text { dapat diketahui nilai kinerja optimal. Menugaskan staff } \\
\text { IT untuk melakukan pengujian terhadap sistem SIAKAD } \\
\text { dan dibuat laporan terkait resiko masalah yang terjadi } \\
\text { terhadap layanan. }\end{array}$ \\
\hline
\end{tabular}

\subsection{Rekomendasi Akhir}

Kesenjangan yang terjadi perlu dilakukan perumusan rekomendasi perbaikan untuk mencapai tingkat kematangan yang diharapkan. Penanganan kesenjangan (gap) diperlukan tindakan perbaikan secara berkelanjutan dan optimal agar sistem berjalan lebih baik dan memaksimalkan potensi yang ada. Berikut ini rekomendasi DS1:

1) Melakukan monitoring atas pengelolaan pelayanan secara rutin.

2) Melakukan sosialisasi terhadap mahasiswa ketika ada perubahan terhadap sistem terkait penambahan fitur layanan.

3) Melakukan pelatihan terhadap staff terkait penggunaan perangkat dalam menunjang pelayanan.

4) Berkoordinasi dengan staff IT dan pihak bank dalam menghubungkan layanan SIAKAD dengan bank agar pembayaran dapat terverifikasi secara otomatis.

Sedangkan untuk domain DS5 hasil rumusan rekomendasinya sebagai berikut:

1) Monitoring keamanan sistem dan melakukan backup sistem secara teratur, mencatat sumber data yang masuk.

2) Melakukan sosialisasi terhadap mahasiswa terkait tanggung jawab dalam mengamankan akun masing-masing.
3) Menerapkan tanggal lahir mahasiswa sebagai default password

4) Melakukan koordinasi dengan staff dalam melakukan pelatihan terkait keamanan sistem serta perangkat yang digunakan. Menunjuk staff IT agar melakukan pengujian terhadap keamanan sistem secara berkala.

Domain DS10 hasil rumusan rekomendasinya sebagai berikut:

1) Melakukan pemeriksaan secara rutin terhadap prosedur dan sistem yang berjalan.

2) Mendata masalah yang muncul dan melakukan perbaikan dengan mencari akar masalahnya.

3) melakukan perubahan kode SQL pada sistem SIAKAD bagian KRS agar mahasiswa dapat mengambil matakuliah di kelas lain.

4) Melakukan pelatihan terhadap staff terkait pengelolaan masalah dan perangkat yang digunakan.

\section{PENUTUP}

\subsection{Kesimpulan}

Berdasarkan hasil penelitian yang dilakukan maka dapat diambil beberapa kesimpulan sebagai berikut:

a. Tingkat kematangan Sistem Informasi Akademik (SIAKAD) pada STIKES 
Aisyiyah Surakarta berdasarkan nilai ratarata tersebut berada pada level 4 (Managed and Measureable) yaitu terkelola dan terukur, artinya pihak Instansi telah peduli dan mengetahui pentingnya manajemen tingkat layanan, keamanan sistem dan manajemen masalah. Memiliki prosedur yang sesuai standar, sistem sudah terkelola dengan baik, hanya saja masih ada beberapa yang kurang optimal dalam pelaksanaan seperti kurangnya pemahaman mahasiswa terhadap keamanan akun.

b. Rekomendasi dari penelian ini adalah Cermati setiap aktifitas yang ada di sistem SIAKAD, melakukan backup sistem secara berkala, mencatat segala resiko masalah yang dapat muncul, membuat pedoman dalam menggunakan layanan SIAKAD secara tertulis dan membagikan tanggung jawab sesuai jobdesk masingmasing staff. Sosialisasi kepada mahasiswa secara berkala dan menugaskan staff IT melakukan pengujian keamanan sistem, pelatihan kepada staff yang terlibat dalam pengelolaan layanan SIAKAD, Koordinasi dengan staff IT dan pihak bank dalam menghubungkan layanan SIAKAD dengan bank agar pembayaran dapat terverifikasi secara otomatis, menerapkan tanggal lahir mahasiswa sebagai default password, melakukan perubahan kode $S Q L$ pada sistem SIAKAD.

\subsection{Saran}

a. Melakukan pendataan terhadap setiap masalah yang muncul seperti pelanggaran keamanan dan kendala dalam melakukan pelayanan, membuat pedoman penggunaan sistem SIAKAD secara tertulis dan melakukan sosialisasi secara berkala setiap adanya perubahan maupun penambahan fitur layanan atau keamanan sistem kepada pengguna, melakukan koordinasi dengan bank untuk menghubungkan sistem SIAKAD dengan sistem pembayaran bank.

b. Saran bagi penelitian selanjutnya menambah cakupan domain DS2 (Pengaturan layanan dengan pihak ketiga), DS7 (Mendidik dan melatih user) dan DS9 (Mengatur konfigurasi), serta melakukan validasi terhadap rekomendasi untuk mengetahui apakah rekomendasi yang telah dirumuskan dalam penelitian ini dapat diterapkan instansi dengan baik atau tidak.

\section{DAFTAR PUSTAKA}

[1] E. Mahardika, "Analisis Tata Kelola Ti Berdasarkan Domain Delivery and Support 5 ( Ds5 ) Untuk Memastikan Keamanan Sistem Menggunakan Framework Cobit 4. 1 Pada Universitas Dian," vol. 5, pp. 1-9.

[2] N. Purwati, "Audit Sistem Informasi Akademik Menggunakan Framework Cobit 4.1 (Studi Kasus Ibi Darmajaya)," J. Inform. Darmajaya, vol. 14, no. 2, pp. 134152, 2014.

[3] R. N. Rifai and Wasilah, "Penggunaan Metode COBIT FRAMEWORK 4.1 dalam mengaudit Sistem Informasi Akademik (SIAKAD) pada IAIN Raden Lampung," Pengguna. Metod. COBIT Framew. 4.1 dalam mengaudit Sist. Inf. Akad. pada IAIN Raden Lampung, vol. 01, no. 01, pp. 83-91, 2015.

[4] S. Arikunto, "Evaluasi Program Pendidikan," PT bumi aksara, 2008.

[5] J. SATZINGER, Systems Analysis and Design in a Changing Word Fifth Edition. 2010.

[6] Krismaji, "Pengertian Informasi menurut krismaji," in Sistem Informasi Akuntansi, 2015.

[7] Abdul Kadir, "Pengenalan Sistem Informasi Edisi Revisi," Edisi Revisi. 2014.

[8] Imelda and M. Erik, "Perancangan Sistem Informasi Akademik Pada Sekolah Dasar Negeri Sukajadi 9 Bandung," J. Teknol. dan Inf. UNIKOM, 2013.

[9] COBIT 5, "COBIT 5: Process Assessment Model (PAM)," ISACA, 2013. .

[10] ITGI, IT Governance Implementation Guide: Using CobiT and Val IT - Second Edition. 2007.

[11] T. P. Ryan, Sample Size Determination and Power. 2013.

[12] Setiyowati, S. Siswanti, A. Kusumaningrum, and K. Sandradewi, "Peningkatan Kematangan Proses Tl: Penilaian, Rekomendasi dan Validasi (Studi Kasus Sistem Informasi IPOS)," J. IIm. SINUS, 2019. 